OPEN ACCESS

Edited by:

Nataliya Titova,

Pirogov Russian National Research

Medical University, Russia

Reviewed by:

Zhong Pei,

Department of Neurology, The First

Affiliated Hospital, Sun Yat-Sen

University, China

Matteo Bologna,

Sapienza Università di Roma, Italy

*Correspondence:

Mohammad Hadi Aarabi

mohammadhadiarabi@gmail.com

Specialty section:

This article was submitted to

Movement Disorders,

a section of the journal

Frontiers in Neurology

Received: 26 February 2018

Accepted: 25 May 2018

Published: 26 June 2018

Citation:

Ghazi Sherbaf F, Rostam Abadi Y,

Mojtahed Zadeh M

Ashraf-Ganjouei A, Sanjari

Moghaddam H and Aarabi MH (2018) Microstructural Changes in Patients With Parkinson's Disease Comorbid With REM Sleep Behaviour Disorder and Depressive Symptoms.

Front. Neurol. 9:441.

doi: 10.3389/fneur.2018.00441

\section{Microstructural Changes in Patients With Parkinson's Disease Comorbid With REM Sleep Behaviour Disorder and Depressive Symptoms}

\author{
Farzaneh Ghazi Sherbaf, Yasna Rostam Abadi, Mahtab Mojtahed Zadeh, \\ Amir Ashraf-Ganjouei, Hossein Sanjari Moghaddam and Mohammad Hadi Aarabi*
}

Faculty of Medicine, Tehran University of Medical Sciences, Tehran, Iran

The diagnosis of Parkinson's disease (PD) is currently anchored on clinical motor symptoms, which appear more than 20 years after initiation of the neurotoxicity. Extra-nigral involvement in the onset of PD with probable nonmotor manifestations before the development of motor signs, lead us to the preclinical (asymptomatic) or prodromal stages of the disease (various nonmotor or subtle motor signs). REM sleep behavior disorder (RBD) and depression are established prodromal clinical markers of PD and predict worse motor and cognitive outcomes. Nevertheless, taken by themselves, these markers are not yet claimed to be practical in identifying high-risk individuals. Combining promising markers may be helpful in a reliable diagnosis of early PD. Therefore, we aimed to detect neural correlates of RBD and depression in 93 treatment-naïve and nondemented early PD by means of diffusion MRI connectometry. Comparing four groups of PD patients with or without comorbid RBD and/or depressive symptoms with each other and with 31 healthy controls, we found that these two non-motor symptoms are associated with lower connectivity in several white matter tracts including the cerebellar peduncles, corpus callosum and long association fibers such as cingulum, fornix, and inferior longitudinal fasciculus. For the first time, we were able to detect the involvement of short association fibers (U-fibers) in PD neurodegenerative process. Longitudinal studies on larger sample groups are needed to further investigate the reported associations.

Keywords: Parkinson's disease, REM sleep behavior disorder, depression, connectometry, diffusion MRI

\section{INTRODUCTION}

Parkinson's disease (PD), a form of $\alpha$-synucleinopathy neurodegeneration (1), is manifested by a heterogeneous combination of motor and non-motor symptoms (NMS) (2). PD is classically diagnosed based on its cardinal motor symptoms relatively late in the course of the disease, years or even decades after the initiation of neurotoxicity. Thus, the golden time to halt the disease progression is missed. Searching for markers to diagnose PD in the early stage of the disease, a critical opportunity for neuroprotective interventions remains a hot topic (3). 
Rapid Eye movement (REM) sleep behavior disorder (RBD), characterized by unpleasant dreams and loss of normal muscle atonia (4), has by far proved to be the strongest precursor of upcoming PD (3) and with more than $75 \%$ conversion rate, is considered as an evolving synucleinopathy (5-7). With an estimated prevalence of $15-60 \%$ in PD patients (8), baseline $\mathrm{RBD}$ is attributed to more aggressive clinical subtype with worse motor and non-motor symptoms, especially depressive disorders and cognitive decline (9). Besides high specificity and prognostic value, its low predictive sensitivity and long lead time to the development of parkinsonism bring challenges in practice. Combining RBD with another prodromal symptom may solve this task by increasing the risk of conversion (10).

Depression is another established clinical prodromal marker $(3,7)$ and is the main culprit in a lower quality of life in PD patients (11). Depression together with RBD play as potential interactive risk factors for the development of dementia in PD which is associated with more advanced disease and poorer prognosis (12-14). Depression has multitude neural and clinical correlates with RBD. Depressed mood is often associated with disrupted REM sleep structure such as decreased latency, longer duration and more rapid eye movements, which may precede the onset of depressive episodes or even persist after complete remission with an increased rate of relapse or recurrence and poor treatment response (15-18). Furthermore, studies on healthy relatives of depressed patients have shown that REM sleep disturbances can predict the development of depressive episodes (19-22). This indicates that REM sleep dysregulation is not merely secondary but rather share underlying pathologies with depression (23-25). The frequency of Depression and its severity are also shown to be related to RBD and other sleep disturbances in PD $(9,26,27)$. Some studies on depressed patients with idiopathic RBD (iRBD) have supported the assumption that this comorbidity might underpin and accelerate the neurodegenerative process (28-30). Interestingly, Wing et al. proved depression as a potential predictor of upcoming PD in following a cohort of iRBD patients (31). Remarked subcortical Lewy bodies in late-life depression (32) further supports this proposed link between depression and RBD.

Accumulating evidence suggests that white matter damage underlies the heterogenous manifestation of PD symptomatology (33). Although the pathogenesis of PD is still unclear, it is speculated that $\alpha$-synuclein species spread as a prion-like pattern through axons and cause disruption in the white matter integrity via mitochondrial damage and glial activation (34). In this regard, diffusion MRI (dMRI) is a promising tool to measure white matter microstructure in vivo and has shed light through the knowledge of involved neural networks in PD in association with its distinct features. DMRI connectomery is a powerful analytical method that probes significant between-group differences within subcomponents of a neural pathway, rather than the entire pathway. Conventional diffusion tensor approaches track the entire pathway, which will inevitably contain fibers not strongly associated with study variables. This will result in higher sensitivity and lower type II error using connectometry approach by focusing only on significant variabilities (35). Furthermore, connectometry relies on Spin Distribution Function (SDF) to measure the density of water diffusion for any direction of a voxel and reveals the so-called "local connectome fingerprint" which is highly specific to each individual (36). Ability to quantify the degree of connectivity between adjacent voxels within a neural fascicle, local connectome, has opened a new door to investigate pathological insults on the unique configuration of white matter microstructure.

In two previous studies, we have tried to discover whether RBD and depression can lead us to white matter degeneration signature of early PD, comparing two groups of depressed (dPD) and non-depressed PD patients (ndPD) with comorbid RBD (37) and comparing two groups of $\mathrm{APD}$ and ndPD without comorbid RBD (38) through dMRI connectometry. RBD and depressive symptoms both have been proposed as markers of prodromal $\mathrm{PD}$ and with possible cumulative effect on progression to PD and its severe subtypes and each can predict worse outcomes in $\mathrm{PD}$ or the other. In this study, which is an extension of two previous mentioned studies, we aimed to track differences in white matter connectivity in four groups of treatment-naïve early PD patients with and without comorbid RBD and/or depressive symptoms compared to healthy controls (HC) with added within PD subgroups comparisons.

\section{MATERIALS AND METHODS}

\section{Participants}

Participants, PD patients and HC, involved in this research were recruited from Parkinson's Progression Markers Initiative (PPMI, http://www.ppmi-info.org/). The study was approved by the institutional review board of all participating sites. Written informed consent was obtained from all participants before study enrolment. The study was performed in accordance with relevant guidelines and regulations (39). These participants were tested and confirmed negative for any neurological disorders apart from PD. The participants' PD status was confirmed by Movement Disorder Society-Unified Parkinson's Disease Rating Scale (MDS-UPDRS), and the loss of dopaminergic neurons was observed on DAT scans.

We analyzed only drug-naïve cases with available diffusion weighted imaging (DWI) in baseline visit after performing automated quality-control steps expressed by Fang-Chen Yeh, using q-space diffeomorphic reconstruction (QSDR) (40). This method is based on checking how compatible the quantitative anisotropy (QA) value of each voxel is with the reconstructed QA map. Subjects were excluded if imaging failed specific quality control criteria. Finally, a total of 93 drug-naïve early PD patients and 31 age-matched and sex-matched HC with good imaging quality were enrolled in this study. Clinical measures included disease duration, motor section (III) of UPDRS, Hoehn and Yahr (H\&Y staging), Montreal Cognitive Assessment (MoCA), Epworth Sleepiness Scale (ESS) for daytime sleepiness, and the University of Pennsylvania Smell Identification Test (UPSIT) for olfaction function. Depression was assessed using the Geriatric Depression Scale (GDS), with a cut-off score of 5 or more indicating clinically significant symptoms (41). GDS is an easy to use, self-report screening and diagnostic tool with good reliability and validity to discriminate minor and major depressive disorders from nondepressive disorder in PD patients of all ages, particularly 
elders (41). It is recommended for use by the Movement Disorders Society to screen for symptoms of depression in PD individuals (www.movementdisorders.org/MDS/Education/ Rating-Scales.htm). RBD was assessed using REM Sleep Behavior Disorder Screening Questionnaire (RBDSQ), with a cut-off score of 5 or above to detect probable RBD $(42,43)$. Based on GDS and RBDSQ, PD patients were divided into four groups of 14 patients with depression and RBD (DEP+/RBD+), 16 without depression and with RBD (DEP-/RBD+), 43 with depression and without RBD (DEP+/RBD-), and 20 without depression and without RBD (DEP-/RBD-).

\section{Data Acquisition}

Data used in the preparation of this article were obtained from PPMI database (www.ppmiinfo.org/data) (39). This dataset was acquired on 3 Tesla Siemens scanners, producing 64 diffusion MRI (repetition time $=7748 \mathrm{MS}$, echo time $=86 \mathrm{~ms}$; voxel size: $2.0 \times 2.0 \times 2.0 \mathrm{~mm} 3$; field of view $=224 \times 224 \mathrm{~mm}$ ) at $\mathrm{b}=1,000 \mathrm{~s} / \mathrm{mm}^{2}$ and one b0 image along with 3D T1-weighted structural scans (repetition time $=8.2 \mathrm{~ms}$, echo time $=3.7 \mathrm{~ms}$; flip angle $=8^{\circ}$, voxel size: $1.0 \times 1.0 \times 1.0 \mathrm{~mm}^{3}$; field of view $=240 \mathrm{~mm}$, acquisition matrix $=240 \times 240$ ).

\section{Diffusion MRI Processing}

The diffusion MRI data were corrected for subject motion, eddy current distortions, and susceptibility artifacts due to the magnetic field inhomogeneity using Explore DTI toolbox (44). We performed quality control analysis on the subject's signals based on the goodness-of-fit value given in QSDR reconstruction of fibers. Each QSDR reconstruction file has a goodness-of-fit value quantified by R2. For example, an R82 indicates a goodnessof-fit between of the subject and template of 0.82 total. We excluded cases in which the $\mathrm{R} 2$ value did not reach a threshold of 0.6 otherwise.

\section{Diffusion MRI Connectometry}

The diffusion data were reconstructed in the Montreal Neurological Institute (MNI) space using QSDR to obtain the SDF (45), to detect the differences between groups. Quantitative anisotropy (QA) is one of the several diffusion indices derived from spin density, i.e., SDF (46). QA of each fiber orientation gives the peak value of water density in that direction. More precisely, in contrast to tensor-derived measures such as fractional anisotropy (FA) which are defined for each voxel and rely on diffusivity, QA is defined for each fiber orientation and is based on density. Therefore, diffusivity measures reflect the intactness of fibers, while QA quantifies the total diffusing water or "connectivity." As a result, QA has successfully overcome the shortage of conventional tensor measures on crossing fibers. Another advantage of QA over diffusivity metrics is that it is not affected by partial volume defect, as it is derived from spin density (47). We used diffusion MRI connectometry to identify white matter tracts in which QA was significantly different between two groups of PD patients with different degrees of depression and RBD, and comparing each PD group to HC. Resulting uncorrected output was corrected for multiple comparisons by false discovery rate (FDR). A deterministic fiber tracking algorithm was conducted along the core pathway of the fiber bundle to connect the selected local connectomes (48). Tracts with QA $>0.1$, angle threshold lesser than $40^{\circ}$ and tract length $>40 \mathrm{~mm}$ were included. To estimate the false discovery rate, a total of 2,000 randomized permutations were applied to the group label to obtain the null distribution of the track length. A T-score threshold of 2.5 was assigned to select local connectomes, and the local connectomes were tracked using a deterministic fiber tracking algorithm. Permutation testing allows for estimating and correcting the FDR of Type-I error inflation due to multiple comparisons. The analysis was conducted using publicly available software DSI Studio (http:// dsi-studio.labsolver.org), released in 5th April 2018.

\section{Statistical Analysis}

IBM SPSS Statistics for Windows, version 22 (IBM Corp., Armonk, N.Y., USA) was used to analyse the demographic and clinical data. Probability graphics and Shapiro-Wilk test were used to check the compliance of variables with normal distribution. For normally distributed variables, one-way analysis of variance (ANOVA) was used to assess differences of means between groups. Kruskal-Wallis test was used to determine whether there are any statistically significant differences within continuous variables without normal distribution. Pearson's chisquare was used to test nominal variables across groups. Finally, $P<0.05$ were considered statistically significant.

\section{RESULTS}

\section{Demographic and Clinical Measures}

PD patients in four groups were matched in their age, sex, disease duration and years of education. Patients were also comparable based on their degree of motor impairment (UDPRSIII and H\&Y) after controlling for age, sex, and disease duration. The cognitive state (MoCA), olfaction function (UPSIT), and daytime sleepiness (ESS) did not differ between four PD groups (Table 1). There are few discrepancies between PD patients enrolled in this study and those investigated in our two previous studies, as we attempted to include patients matched in their demographic, motor and other non-motor symptoms other than depression and $\mathrm{RBD}$ in the present study. Eleven patients in the $\mathrm{DEP}+/ \mathrm{RBD}+$ group, eight patients in the DEP-/RBD+ group, 19 patients in the $\mathrm{DEP}+/ \mathrm{RBD}$ - group, and 14 patients in the DEP-/RBD- group were at their stage 2 of $\mathrm{H} \& \mathrm{Y}$, indicative of bilateral involvement without disturbance in balance. The rest of the patients were all in stage 1 of H\&Y scaling compatible with mild symptoms of unilateral involvement. None of the patients in any group were demented as they all scored above the cut-off score of 21 on the MoCA. HC were matched with PD patients regarding age, sex, handedness, education years, MoCA, and ESS scores, while performed better than PD patients on GDS, RBD, and UPSIT.

\section{PD Groups vs. HC Imaging Analysis}

As outlined in Table 2, all four groups of PD patients showed lower connectivity in superior longitudinal fasciculus and Ufibers of parietal lobe and motor and pre-motor areas of the 
TABLE 1 | Demographic and baseline clinical information of healthy controls and patients with Parkinson's disease with or without comorbid RBD and/or depression.

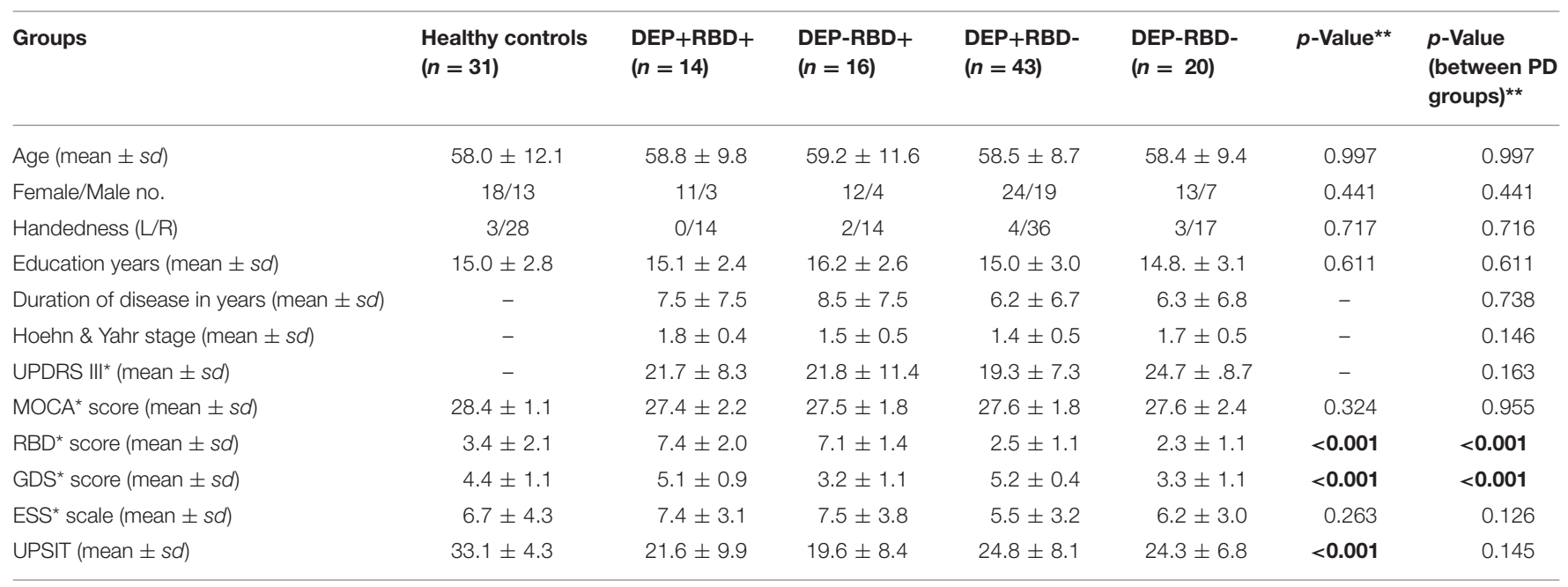

*UPDRS III, Unified Parkinson's Disease Rating Scale part III; ESS, Epworth Sleepiness Scale; MoCA, Montreal Cognitive Assessment; RBD, REM sleep Behaviour Disorder Screening

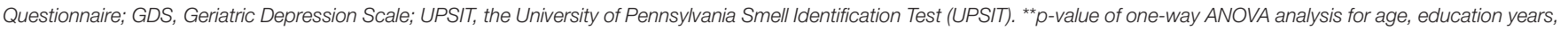
disease duration, and UPSIT; Pearson Chi-square for gender, handedness, and H\&Y stage; and Kruskal-Wallis test for ESS, UPRDS part III, GDS scale, MoCA score, and RBDSQ. $P<0.05$ are considered statistically significant.

TABLE 2 | Regions with significantly reduced quantitative anisotropy comparing each group of PD patients with healthy controls.

\begin{tabular}{|c|c|c|c|}
\hline $\begin{array}{l}\text { PD RBD+/DEP+ } \\
\text { vs. HC } \\
(\text { FDR }=0.01)\end{array}$ & $\begin{array}{l}\text { PD Dep-/RBD+ } \\
\text { vs. HC } \\
\text { (FDR = 0.02) }\end{array}$ & $\begin{array}{l}\text { Dep+/RBD-vs. } \\
\text { HC } \\
\text { (FDR = 0.001) }\end{array}$ & $\begin{array}{l}\text { DEP-/RBD-vs. } \\
\text { HC } \\
\text { (FDR = 0.036) }\end{array}$ \\
\hline B-SLF & B-SLF & B-SLF & B-SLF \\
\hline B-U-fiber & B-U-fiber & L-U-fiber & R-U-fiber \\
\hline L-ILF & B-cingulum & L-ILF & R-cingulum \\
\hline body of CC & & B-cingulum & \\
\hline
\end{tabular}

$B$, bilateral; L, left; $R$, right; $S L F$, superior longitudinal fasciculus; ILF, inferior longitudinal fasciculus; CC, corpus callosum; FDR, false discovery rate.

frontal lobe. Left inferior longitudinal fasciculus (ILF) was only disrupted in the PD groups with comorbid depression, i.e., $\mathrm{DEP}+/ \mathrm{RBD}-$ and $\mathrm{DEP}+/ \mathrm{RBD}+$. Cingulum had lower connectivity in all $\mathrm{PD}$ patients except $\mathrm{RBD}+/ \mathrm{DEP}+$. This group instead showed lower connectivity in the body of corpus callosum (CC).

\section{Between-Group Imaging Analyses of PD Patients}

Compared with PD DEP-/RBD+ patients, PD DEP+/RBD+ patients showed decreased connectivity in the right cingulum, left ILF, splenium, and body of the CC $(F D R=0.03)$ (Figure 1). As shown in Figure 2, the PD DEP+/RBD + group demonstrated decreased connectivity in the genu, splenium, and body of CC, left ILF, left fornix, and right superior cerebellar peduncle $(\mathrm{SCP})$ in contrast to PD DEP+/RBD- (FDR $=0.02$ ). The group differences between $\mathrm{PD} \mathrm{DEP}+/ \mathrm{RBD}+$ patients and PD DEP/RBD- were that connectivity in PD DEP-/RBD- was higher than that in $\mathrm{PD} \mathrm{DEP}+/ \mathrm{RBD}+$ patients in the genu, splenium and body of CC, bilateral cingulum, left ILF, left fornix, right SCP, and right inferior fronto-occipital fasciculus (IFOF) $(F D R=0.01)$.

Compared with PD DEP-/RBD- patients, PD DEP-/RBD+ patients showed decreased connectivity in the bilateral cingulum, bilateral fornix, left ILF, genu, and body of CC, middle cerebellar peduncle (MCP), bilateral SCP, right uncinate fasciculus (UF), and left cerebro-cortical pathway $(\mathrm{CST})(\mathrm{FDR}=0.03)$. These were almost the same results of comparison between $\mathrm{PD}$ $\mathrm{DEP}+/ \mathrm{RBD}$ - with the DEP-/RBD+, except for the right fornix, left cingulum, and left ILF (FDR = 0.006).

Finally, PD DEP+/RBD- patients showed decreased connectivity in the bilateral cingulum, bilateral fornix, bilateral ILF, left UF, right CST and genu, splenium, and body of CC compared to PD DEP-/RBD- $(F D R=0.02)$. Table 3 summarizes the significant regions of lower connectivity in between-group analyses.

\section{DISCUSSION}

In this study, we investigated the neural underpinnings of $\mathrm{RBD}$ and depression as clinical PD prodromal markers with more severe outcome mainly of the motor and cognitive function. RBD not only predicts upcoming PD but also warns the development of non-tremor dominant motor subtype with a diversity of other NMS such as depression and dementia (49). Recent evidence has exposed the role of widespread white matter disruption underlying heterogenous symptoms of $\mathrm{PD}$, including commissural, projection and long association fibers (33). Previous studies have mostly relied on diffusion tensor imaging (DTI), which has major limitations in detecting pathologies in areas of high crossing fibers such as near cortical structures. Using connectometry analysis, which successfully overcomes this pitfall (50), we were able to capture the novel contribution of U-fibers in PD. U-fibers are short association fibers which run between white matter and cortex and connect adjacent gyri and participate in higher functions of the brain. As these particular fibers have low metabolic rate and high blood supply, they are relatively spared in vascular disorders such as stroke. In contrast, pathologies with glial insult, such as multiple sclerosis, are shown to result in early involvement of U-fibers 

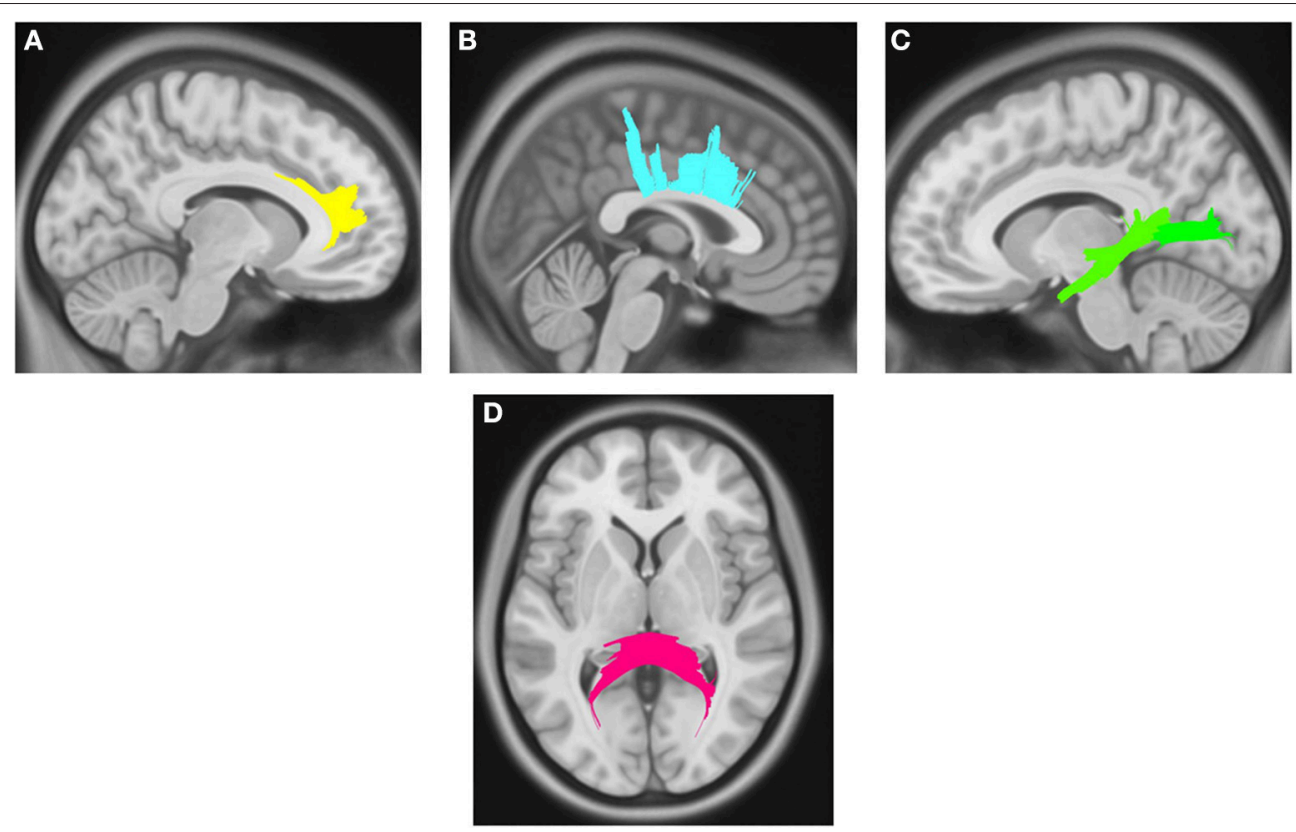

FIGURE 1 | White matter pathways with significantly reduced quantitative anisotropy in PD DEP+RBD+ vs. PD DEP-RBD+ (FDR $=0.03)$. (A) right cingulum, (B) body of the corpus callosum, (C) left inferior longitudinal fasciculus, (D) splenium. The results are overlaid on ICBM152 (mni_icbm152_t1) from the McConnell Brain Imaging Centre using DSI-STUDIO software.
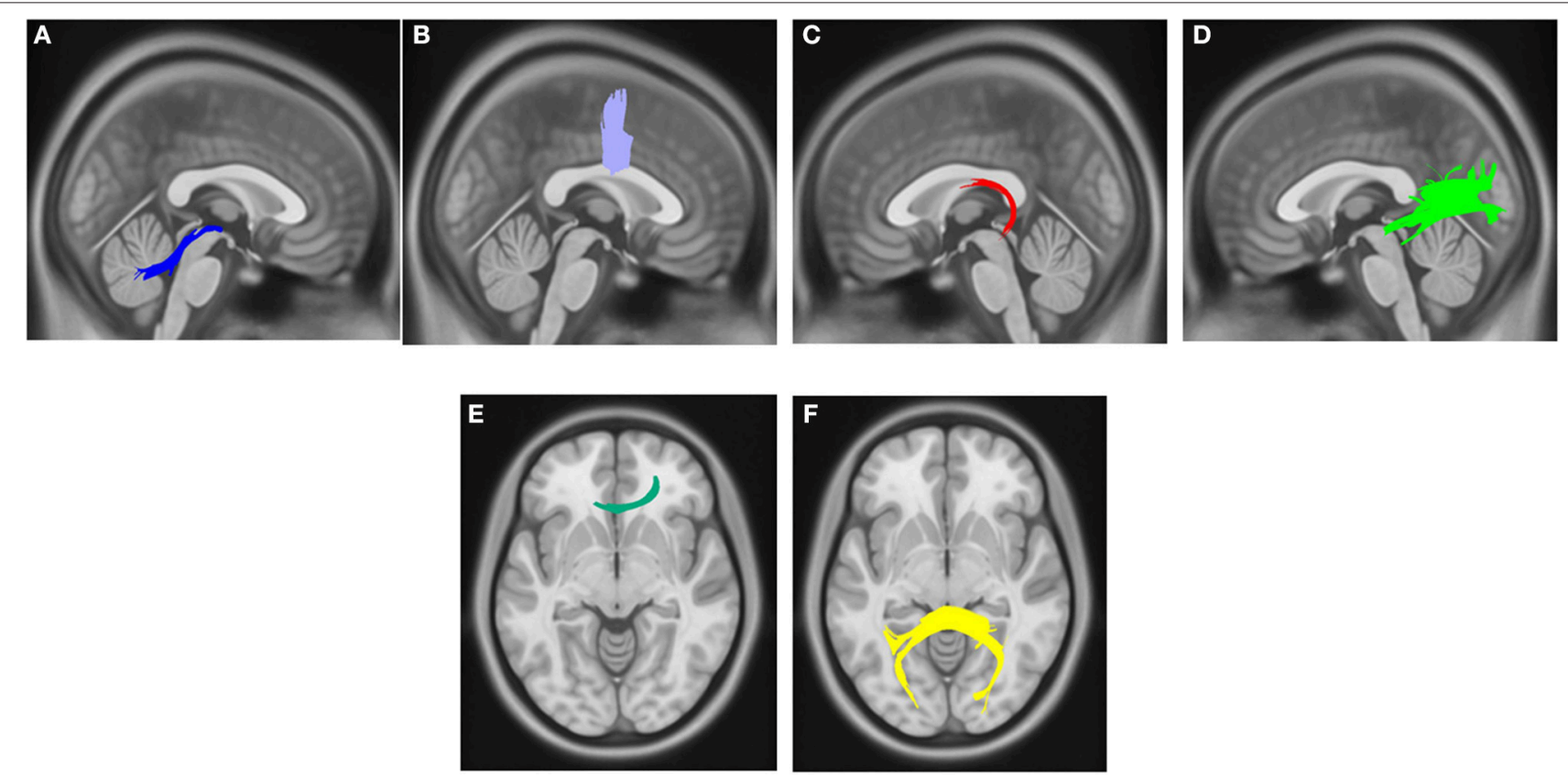

FIGURE 2 | White matter pathways with significantly reduced quantitative anisotropy in PD DEP+RBD+ vs. PD DEP+RBD- (FDR $=0.02)$. (A) right superior cerebellar peduncle, (B) body of the corpus callosum, (C) left fornix, (D) left inferior longitudinal fasciculus, (E) genu, (F) splenium. The results are overlaid on ICBM152 (mni_icbm152_t1) from the McConnell Brain Imaging Centre using DSI-STUDIO software.

and the subsequent cognitive malperformance in such patients (51). Glial dysfunction is one of the key events in initiation and progression of neurodegenerative processes as well (52-54).
Therefore, it seems that $\mathrm{U}$-fibers can be potentially affected in PD. This is a thought-provoking result that should be addressed in future research. 
TABLE 3 | Regions with significantly different connectivity in between group comparing of PD patients with or without comorbid RBD and/or depression.

\begin{tabular}{|c|c|c|}
\hline $\begin{array}{l}P D D E P+/ R B D+ \\
\text { vs. } P D D E P-/ R B D- \\
\text { (FDR }=0.01)\end{array}$ & $\begin{array}{l}P D D E P+/ R B D+\text { vs. } \\
P D D E P-/ R B D+ \\
\text { (FDR }=0.03 \text { ) }\end{array}$ & $\begin{array}{l}P D D E P+/ R B D+\text { vs. } \\
P D D E P+/ R B D- \\
\text { (FDR }=0.02)\end{array}$ \\
\hline $\begin{array}{l}\text { R-SCP } \\
\text { B-cingulum } \\
\text { L-fornix } \\
\text { L-ILF } \\
\text { R-IFOF } \\
\text { Genu, body and } \\
\text { splenium of CC }\end{array}$ & $\begin{array}{l}\text { R-Cingulum } \\
\text { L-ILF } \\
\text { Splenium and body of } \\
\text { CC } \\
\text { (previous study: Fornix, } \\
\text { genu, L-MCP, R-CST, } \\
\text { R-cing, L-ILF) }\end{array}$ & $\begin{array}{l}\text { R-SCP } \\
\text { L-ILF } \\
\text { L-fornix } \\
\text { Genu, body and } \\
\text { splenium of CC }\end{array}$ \\
\hline $\begin{array}{l}P D D E P-/ R B D+\text { vs. } \\
P D D E P-/ R B D- \\
\text { (FDR }=0.03 \text { ) }\end{array}$ & $\begin{array}{l}P D D E P+/ R B D-\text { vs. } \\
\text { PD } D E P-/ R B D- \\
\text { (FDR = 0.02) }\end{array}$ & $\begin{array}{l}P D D E P-/ R B D+\text { vs. } \\
P D D E P+/ R B D- \\
\text { (FDR }=0.006)\end{array}$ \\
\hline $\begin{array}{l}\text { B-SCP } \\
\text { MCP } \\
\text { B-cingulum } \\
\text { B-fornix } \\
\text { L-ILF } \\
\text { Genu and body of } \\
\text { CC } \\
\text { R-UF } \\
\text { L-CST }\end{array}$ & $\begin{array}{l}\text { B-cingulum } \\
\text { B-fornix } \\
\text { B-ILF } \\
\text { Genu, body and } \\
\text { splenium of CC } \\
\text { L-UF } \\
\text { R-CST } \\
\text { (Previous study: } \\
\text { R-IFOF, MCP Genu, UF, } \\
\text { L-ILF, R-CST, Fornix) }\end{array}$ & $\begin{array}{l}\text { B-SCP } \\
\text { MCP } \\
\text { R-cingulum } \\
\text { L-fornix } \\
\text { Genu and body of CC } \\
\text { L-external capsule } \\
\text { L-CST }\end{array}$ \\
\hline
\end{tabular}

The left groups vs. the right groups showed lower quantitative anisotropy in the areas listed. $B$, bilateral; $R$, right; $L$, left; $S C P$, superior cerebellar peduncle; $M C P$, middle cerebellar peduncle; ILF, inferior longitudinal fasciculus; UF, uncinate fasciculus; CST, cerebrospinal tract; IFOF, inferior fronto-occipital fasciculus; CC, corpus callosum; FDR, false discovery rate.

Among other fibers with lower connectivity, like U-fibers, SLF also consistently differed between PD patients and HC regardless of the comorbid RBD or depression. Previous studies have specified the lower integrity of SLF associated with several domains of cognitive decline from mild cognitive impairment to dementia (55-58), and also in non-tremor motor phenotypes of PD such as freezing of gait $(59,60)$, bradykinesia (61), and postural instability (62), which have poor prognostic implications. SLF is a long association fiber that originates from posterior regions of the brain and projects to the frontal lobe. However, among few studies which have investigated DTI findings in relation to depression, lower FA in the left SLF near the midline and superior frontal lobe is reported in dPD versus ndPD in one whole brain study (63). The authors have discussed this finding through the cognitive aspect of depression. A meta-analysis has also implicated the disruption of SLF in major depressive disorder (MDD) (64). However, within-patients analysis of our cohort did not reveal any subgroup-differences in SLF, which would indirectly point toward to non-contribution of this tract with depression and RBD. This is in agreement with our previous studies on $\operatorname{dPD}(37,38,65)$.

ILF was only disrupted in the PD groups with comorbid depression compared to HC. ILF fast and directly integrates visual categorization and recognition data between extrastriate visual cortex and temporal gyri which subsequently project to the limbic structures (66). High-order visual problems such as visually evoked memory and emotional impairments are linked to ILF disruptions, as a key component of the visual-limbic pathway $(67,68)$. ILF is among the main fibers involved in the major depressive disorder, proved by the mentioned metaanalysis of whole brain voxel-based DTI studies (64). The same association was also demonstrated in $\operatorname{dPD}(63,69)$ and mild cognitive impairment and dementia in $\operatorname{PD}(55,58)$ based on whole brain tract-based spatial statistics studies. This finding may signal the higher risk of cognitive impairment in terms of executive and visuospatial dysfunction in dPD. ILF disruption most consistently observed in the left hemisphere is in agreement with the perception that depression is a result of left hemispheric dysfunction (70). Interestingly, it is revealed that right-onset PD predict more severe depressive symptoms in the course of the disease (71). These may explain our finding of ILF lateralization in comorbid depression in PD. Apart from ILF alterations in $\mathrm{dPD}$, our results are also indicative of reduced connectivity in left ILF in DEP-/RBD+ compared to DEP-/RBD-, which is in line with the study by Ford et al. (72). However, few other studies comparing PD-RBD patients with PD-non-RBD have not reached to this association. May longitudinal follow-up of these patients reveal subsequent depressive symptoms followed by ILF disruption, should be investigated in well-designed cohorts.

Cingulate, the prominent limbic structure and the wellknown structure of emotion and cognition activates during REM sleep (73). Cingulum injury has been shown in abnormalities in attention, memory and emotional processing (74). Existing literature is already enriched with cingulum associations in depression and its pathognomonic REM sleep dysregulations $(75,76)$ and also depression, apathy, impulse control deficit and dementia in PD (77-80). More severe lesions of this tract predispose to poorer treatment response in late-life depression (81) and is a stimulating target to treat resistant depression (82). This area is also attributed to comorbid RBD in PD patients recruited from PPMI database $(83,84)$. Overall, it is not surprising that disrupted cingulum bundle is correlated with depressive symptoms and RBD in PD patients.

CC with more than 200 million axonal projections, is the largest fiber bundle in the central nervous system, which actively transfers information between homologous areas of two cerebral hemispheres (85). This commissure has a major role in the regulation of cognitive and emotional function and bilateral limb movement (86). Extensive corpus callosal damage is described in early PD (87), which becomes more severe with motor worsening (88). Reduction of callosal integrity is implicated in the freezing of gait and postural instability in non-tremor dominant PD (89). This phenotype is more often accompanied by cognitive decline and mood disorders $(33,90)$. In line with these observations, diffusion MRI connectometry has revealed reduced integrity in CC in the neuropathology of comorbid RBD (84) and depression (65) in PD. Same association is shown regarding cognitive decline and its severity in $\mathrm{PD}$ (33).

The results of between PD subgroups evaluation showed that superior and middle cerebellar peduncles have lower connectivity consistently comparing PD patients with RBD compared to those without RBD. Cerebellum has heavy connections to the cerebral cortex via brainstem structures. Disruptions of this circuitry 
and asynchronization of cerebral and cerebellar functions are related to sleep-wake state abnormalities $(91,92)$. As a result, cerebellar pathology is often present in sleep disorders (93), and its cortical volume reduction has been shown in RBD $(83,94)$, although the exact contributed pathways are yet to be elucidated. It is now well documented that sleep has a major role in memory consolidation (95). Cerebellar increased activity during sleep in order to integrate learned motor skills is well-documented (96), and gray matter reductions of the cerebellum have resulted in the impaired consolidation of action memories (97). The interconnected sleep and cerebellar cognitive and motor-related functions may point toward the more severe motor and cognitive impairments associated with PD-RBD (9). Metabolic imaging studies have interestingly proposed cerebellum as a PD prodromal biomarker, as a part of a metabolic network associated with the severe motor subtype of PD (98). Idiopathic RBD patients with altered cerebellar metabolism are also at higher risk of photoconverting to neurodegeneration (99). Our consistent results of significant altered white matter in cerebellar peduncles is in line with disturbed cortico-cerebellar connections in PD-RBD patients in contrast to PD patients without RBD. Another DWI connectometry analysis also has manifested middle cerebellar peduncle as a discriminative indicator between these two groups of patients recruited from PPMI (84). Recent neuroanatomical studies have shown the important role of the cerebellum in emotional regulation and high-order cognitive coordination through extensive networks with the cerebral cortex, limbic system and thalamus via superior and middle cerebellar peduncles (100-105). There is a tendency to lateralization in the cerebellum in processing cognition and affection. Lesions of the right cerebellum, in connection to the left cerebral cortex, result in cognitive dysfunctions and positive or approach related emotional disturbances $(103,106)$. A diffusional kurtosis study has found disrupted superior and middle cerebellar peduncles in related to depression, with a particular relationship between disease duration and right SCP (107). The right posterior cerebellar white matter was also associated with treatment resistance in depression in a voxelbased DTI study (105). Functional brain studies have shown the involvement of cerebellar abnormality in depressed PD and also severe PD $(108,109)$. While connectivity of superior and middle cerebellar peduncles was significantly lower in related to comorbid RBD without depression in this study, reduced connectivity is seen only in right SCP, the main output route from the cerebellum to the left prefrontal cortex, in depressed PD patients with comorbid RBD and there is no such association with depressed PD without concomitant RBD. This may be a result of a small number of patients or may point to the specific patterns of comorbidity of depression and RBD in PD. Future studies with a larger number of patients are needed to investigate the generalizability of these results.

Another white matter structure with consistently differed connectivity in between-patients' subgroups comparison was fornix. Fornix, a limbic structure, is the main output tract of the hippocampus to diencephalon and basal forebrain. This structure is an important component of both episodic memory and emotional circuits (110-112). Fornix degeneration is proposed as a strong predictor of upcoming cognitive impairment, as it precedes hippocampal atrophy (113). Comorbid mild cognitive impairment and late-life depression, a possible representation of neurodegenerative disorders, has been related to reduced FA in fornix (114). This result has also been linked to treatment-refractory major depressive disorder (115). In another DTI studies, higher mean diffusivity (MD) in fornix has been revealed in PD patients (116) and with association with short-term nonverbal memory impairment in these patients (117). Experimental studies on animal models have demonstrated that so-called hypocretin neurons in perifornical region regulate sleep/wake cycle $(118,119)$ and neuronal loss may cause increased REM sleep portion $(120,121)$ and sleep disorders such as narcolepsy $(122,123)$. Interestingly, hypocretin neurotransmission system is shown to be affected in a postmortem study of PD patients (124). Anatomical disruptions are also reported in $\mathrm{iRBD}$ (125) and the generation of excessive daytime sleepiness in PD patients (126). Our previous studies and the current study are the first to directly attribute fornix to comorbid depression and RBD in early PD. Left fornix disruption, resulted in disconnection of the left or verbal sphere of the hippocampus may contribute to memory deficits for verbal stimuli, in contrast to visuospatial input processed in the right side (127). Although executive dysfunction is considered as the hallmark cognitive deficit in PD, it has been cleared that verbal memory impairment has the greatest impact of all cognitive domains in PD (128-132). Poor performance on verbal memory tasks is also shown to be associated with sleep problems such as RBD in PD patients (133). Unsurprisingly, depressive disorders are accompanied by impairment in verbal memory as well (134).

There are some discrepancies in results from the current study and our two previous studies (Table 3). In order to control for the effect of the motor and other non-motor symptoms, we attempted to include patients with matched scores on other tests in the current study. This resulted in overlap in our patient selection from PPMI cohort. Using a new version of DSI studio may have also imposed more precise outcomes. Not using gold-standard diagnostic assessments for RBD and depression, polysomnography and clinically approved depression using DSM criteria, may be a source of error that should be kept in mind in interpreting our results. Despite GDS and RBDSQ scores, PD patients had worse olfaction function compared to $\mathrm{HC}$ and this would have contributed to the observed connectivity differences in the first part of the analysis. Longitudinal studies on larger subgroups of PD patients will address the accuracy of these results and better specify the role of each tract disruption in emergence of comorbid symptoms in heterogenous PD. In other words, tracts with differed connectivity in only within PD patients' comparison, such as cerebellar peduncles which most consistently were attributed to PD-RBD, and fornix in $\mathrm{CPD}-\mathrm{RBD}$ may serve as markers useful for PD subtyping, which would be helpful in establishing better prognostic evaluation and more individualized treatment strategies. Needless to mention that these are preliminary findings that should be approved by future research. 


\section{CONCLUSION}

The results of this study support the entangled pathophysiology of depression and RBD which both predict poor outcomes regarding motor symptoms and cognitive decline in $\mathrm{PD}$ patients. As discussed above, specific commissural (CC), projection (CST, SCP, MCP) and long association fibers (cingulum, fornix, ILF, UF, IFOF) have been previously shown to serve as neural underpinnings of malignant subtypes of $\mathrm{PD}$ besides reputable associations with RBD and depression. So, disruption in these tracts may serve as an underlying pathology of REM sleep and mood dysregulations in early PD which also warn the emergence of debilitating motor and cognitive symptoms. A novel result of this study is the disruption of short association fibers (commonly known as U-fibers) in PD neurodegeneration that should be addressed in future research. A small number of patients in each group and not using gold standard tools to diagnose NMS in PPMI database should raise suspicion as multiple sources of error in this study. Shared neural substrates in RBD and depression in early PD is promising to discover high-risk individuals for future PD. Follow-up studies with larger number of patients will clear whether small regional diversities observed in between-patientsgroups comparisons are linked to a specific pattern of RBD and depression in PD or may be justified by small sample sizes.

\section{ETHICS STATEMENT}

All procedures performed here, including human participants were in accordance with the ethical standards of the institutional research committee and with the 1964 Helsinki declaration and

\section{REFERENCES}

1. Goedert M. Alpha-synuclein and neurodegenerative diseases. Nat Rev Neurosci. (2001) 2:492-501. doi: 10.1038/35081564

2. Berg D, Postuma RB, Bloem B, Chan P, Dubois B, Gasser T, et al. Time to redefine PD? Introductory statement of the MDS Task Force on the definition of Parkinson's disease. Mov Disord. (2014) 29:454-62. doi: $10.1002 / \mathrm{mds} .25844$

3. Postuma RB, Berg D. Advances in markers of prodromal Parkinson disease. Nat Rev Neurol. (2016) 12:622-34. doi: 10.1038/nrneurol.2016.152

4. Mahowald MW, Schenck CH. REM sleep parasomnias. In: Kryger MH, Roth T, Dement C, editors. Principles and Practice of Sleep Medicine, 3rd ed. Philadelphia, PA: W.B. Saunders (2000), p. 724-41.

5. Boeve BF, Silber MH, Ferman TJ, Lucas JA, Parisi JE. Association of REM sleep behavior disorder and neurodegenerative disease may reflect an underlying synucleinopathy. Mov Disord. (2001) 16:622-30. doi: $10.1002 / \mathrm{mds} .1120$

6. Boeve BF, Silber M, Ferman TJ, Lin S, Benarroch E, Schmeichel A, et al. Clinicopathologic correlations in 172 cases of rapid eye movement sleep behavior disorder with or without a coexisting neurologic disorder. Sleep Med. (2013) 14:754-62. doi: 10.1016/j.sleep.2012.10.015

7. Berg D, Postuma RB, Adler CH, Bloem BR, Chan P, Dubois B, et al. MDS research criteria for prodromal Parkinson's disease. Mov Disord. (2015) 30:1600-11. doi: 10.1002/mds.26431

8. Kim Y, Kim YE, Park EO, Shin CW, Kim HJ, Jeon B. REM sleep behavior disorder portends poor prognosis in Parkinson's disease: a systematic review. J Clin Neurosci. (2017) 47:6-13. doi: 10.1016/j.jocn.2017. 09.019 its later amendments or comparable ethical standards. Informed consent was obtained from all individual participants included in the study.

\section{AUTHOR CONTRIBUTIONS}

FG and MA contributed to the conception and design of the study; AA-G, HS, FG, and MA contributed to data collection and analysis; FG, YR, MMZ and MA contributed to writing and revising the manuscript.

\section{ACKNOWLEDGMENTS}

This dataset of this work was funded by grants from the Michael J Fox Foundation for Parkinson's Research, the W Garfield Weston Foundation, and the Alzheimer's Association, the Canadian Institutes for Health Research, and the Natural Sciences and Engineering Research Council of Canada. We thank Christian Beckmann and Simon Eickhoff for their advice on data analysis. Data used in this article were obtained from the Parkinsons Progression Markers Initiative (PPMI) database (www.ppmi-info.org/data). For up-to-date information on the study, visit www.ppmi-info.org. PPMI is sponsored and partially funded by the Michael $J$ Fox Foundation for Parkinsons Research and funding partners, including AbbVie, Avid Radiopharmaceuticals, Biogen, Bristol-Myers Squibb, Covance, GE Healthcare, Genentech, GlaxoSmithKline (GSK), Eli Lilly and Company, Lundbeck, Merck, Meso Scale Discovery (MSD), Pfizer, Piramal Imaging, Roche, Servier, and UCB (www.ppmi-info.org/fundingpartners).

9. Fereshtehnejad SM, Romenets SR, Anang JB, Latreille V, Gagnon JF, Postuma RB. New clinical subtypes of Parkinson disease and their longitudinal progression: a prospective cohort comparison with other phenotypes. JAMA Neurol. (2015) 72:863-73. doi: 10.1001/jamaneurol.2015.0703

10. Jin H, Zhang JR, Shen Y, Liu CF. Clinical significance of REM sleep behavior disorders and other non-motor symptoms of Parkinsonism. Neurosci Bull. (2017) 33:576-84. doi: 10.1007/s12264-017-0164-8

11. van Uem JM, Marinus J, Canning C, van Lummel R, Dodel R, LiepeltScarfone I, et al. Health-related quality of life in patients with Parkinson's disease-a systematic review based on the ICF model. Neurosci Biobehav Rev. (2016) 61:26-34. doi: 10.1016/j.neubiorev.2015.11.014

12. Aarsland D, Andersen K, Larsen J, Lolk A, Nielsen H, Kragh-Sørensen P. Risk of dementia in Parkinson's disease a community-based, prospective study. Neurology (2001) 56:730-6. doi: 10.1212/WNL.56.6.730

13. Postuma RB, Bertrand JA, Montplaisir J, Desjardins C, Vendette M, Rios Romenets S, et al. Rapid eye movement sleep behavior disorder and risk of dementia in Parkinson's disease: a prospective study. Mov Disord. (2012) 27:720-6. doi: $10.1002 / \mathrm{mds} .24939$

14. Zhu K, van Hilten JJ, Marinus J. Predictors of dementia in Parkinson's disease; findings from a 5-year prospective study using the SCOPA-COG. Parkinsonism Relat Disord. (2014) 20:980-5. doi: 10.1016/j.parkreldis.2014. 06.006

15. Benca RM, Obermeyer WH, Thisted RA, Gillin JC. Sleep and psychiatric disorders: a meta-analysis. Arch Gen Psychiatry (1992) 49:651-68.

16. Clark C, Dupont R, Golshan S, Gillin JC, Rapaport MH, Kelsoe JR. Preliminary evidence of an association between increased REM density and poor antidepressant response to partial sleep deprivation. J Affect Disord. (2000) 59:77-83. doi: 10.1016/S0165-0327(99)00135-4 
17. Peterson MJ, Benca RM. Sleep in mood disorders. Sleep Med Clin. (2008) 3:231-49. doi: 10.1016/j.psc.2006.09.003

18. Murphy MJ, Peterson MJ. Sleep disturbances in depression. Sleep Med Clin. (2015) 10:17-23. doi: 10.1016/j.jsmc.2014.11.009

19. Giles DE, Roffwarg HP, Rush AJ. REM latency concordance in depressed family members. Biol Psychiatry (1987) 22:910-4.

20. Giles DE, Biggs MM, Rush AJ, Roffwarg HP. Risk factors in families of unipolar depression. I. psychiatric illness and reduced REM latency. J Affect Disord. (1988) 14:51-9.

21. Giles DE, Kupfer DJ, Roffwarg HP, Rush AJ, Biggs MM, Etzel BA. Polysomnographic parameters in first-degree relatives of unipolar probands. Psychiatry Res. (1989) 27:127-36.

22. Giles DE, Roffwarg HP, Rush AJ. A cross-sectional study of the effects of depression on REM latency. Biol Psychiatry (1990) 28:697-704.

23. Hasler G, Drevets WC, Manji HK, Charney DS. Discovering endophenotypes for major depression. Neuropsychopharmacology (2004) 29:1765. doi: 10.1038/sj.npp.1300506

24. Gottesmann C, Gottesman I. The neurobiological characteristics of rapid eye movement (REM) sleep are candidate endophenotypes of depression, schizophrenia, mental retardation and dementia. Prog Neurobiol. (2007) 81:237-50. doi: 10.1016/j.pneurobio.2007.01.004

25. Modell S, Lauer CJ. Rapid eye movement (REM) sleep: an endophenotype for depression. Curr Psychiatry Rep. (2007) 9:480-5. doi: 10.1007/s11920-007-0065-z

26. Borek LL, Kohn R, Friedman JH. Mood and sleep in Parkinson's disease. J Clin Psychiatry (2006) 67:958-63.

27. Rolinski M, Szewczyk-Krolikowski K, Tomlinson PR, Nithi K, Talbot $\mathrm{K}$, Ben-Shlomo Y, et al. REM sleep behaviour disorder is associated with worse quality of life and other non-motor features in early Parkinson's disease. J Neurol Neurosurg Psychiatry (2014) 85:560-6. doi: 10.1136/jnnp-2013-306104

28. Vilas D, Iranzo A, Pont-Sunyer C, Serradell M, Gaig C, Santamaria J, et al. Brainstem raphe and substantia nigra echogenicity in idiopathic REM sleep behavior disorder with comorbid depression. J Neurol. (2015) 262:1665-72. doi: 10.1007/s00415-015-7745-0

29. Wing YK, Lam SP, Zhang J, Leung E, Ho CL, Chen S, et al. Reduced striatal dopamine transmission in REM sleep behavior disorder comorbid with depression. Neurology (2015) 84:516-22. doi: 10.1212/WNL.0000000000001215

30. Fujishiro H, Okuda M, Iwamoto K, Miyata S, Otake H, Noda A, et al. REM sleep without atonia in middle-aged and older psychiatric patients and Lewy body disease: a case series. Int J Geriatr Psychiatry (2017) 32:397-406. doi: 10.1002/gps.4477

31. Wing YK, Li SX, Mok V, Lam SP, Tsoh J, Chan A, et al. Prospective outcome of rapid eye movement sleep behaviour disorder: psychiatric disorders as a potential early marker of Parkinson's disease. J Neurol Neurosurg Psychiatr. (2012) 83:470-2. doi: 10.1136/jnnp-2011-301232

32. Tsopelas C, Stewart R, Savva GM, Brayne C, Ince P, Thomas A, et al. Neuropathological correlates of late-life depression in older people. $\mathrm{Br} J$ Psychiatry (2011) 198:109-14. doi: 10.1192/bjp.bp.110.078816

33. Hall JM, Ehgoetz Martens KA, Walton CC, O'Callaghan C, Keller PE, Lewis SJ, et al. Diffusion alterations associated with Parkinson's disease symptomatology: A review of the literature. Parkinsonism Relat. Disord. (2016) 33:12-26. doi: 10.1016/j.parkreldis.2016.09.026

34. Lamberts JT, Hildebrandt EN, Brundin P. Spreading of $\alpha$-synuclein in the face of axonal transport deficits in Parkinson's disease: a speculative synthesis. Neurobiol Dis. (2015) 77:276-83. doi: 10.1016/j.nbd.2014.07.002

35. Yeh FC, Badre D, Verstynen T. Connectometry: a statistical approach harnessing the analytical potential of the local connectome. Neuroimage (2016) 125:162-71. doi: 10.1016/j.neuroimage.2015.10.053

36. Yeh FC, Vettel JM, Singh A, Poczos B, Grafton ST, Erickson KI, et al. Quantifying differences and similarities in whole-brain white matter architecture using local connectome fingerprints. PLoS Comput Biol. (2016) 12:e1005203. doi: 10.1371/journal.pcbi.1005203

37. Ghazi Sherbaf F, Rahmani F, Jooyandeh SM, Aarabi MH. Microstructural changes in patients with Parkinson disease and REM sleep behavior disorder: depressive symptoms versus non-depressed. Acta Neurol Belg. (2018). doi: 10.1007/s13760-018-0896-x.. [Epub ahead of print].
38. Ansari M, Adib Moradi S, Ghazi Sherbaf F, Hedayatnia A, Aarabi M. Comparison of structural connectivity in Parkinson's disease with depressive symptoms versus non-depressed: a diffusion MRI connectometry study. Int Psychogeriatr. (2018) doi: 10.1017/S1041610218000170. [Epub ahead of print].

39. Marek K, Jennings D, Lasch S, Siderowf A, Tanner C, Simuni T, et al. The parkinson progression marker initiative (PPMI). Prog Neurobiol. (2011) 95:629-35. doi: 10.1016/j.pneurobio.2011.09.005

40. Zhang Y, Wu IW, Tosun D, Foster E, Schuff N. Progression of regional microstructural degeneration in Parkinson's disease: a multicenter diffusion tensor imaging study. PLOS ONE (2016) 11:e0165540. doi: 10.1371/journal.pone.0165540

41. Torbey E, Pachana NA, Dissanayaka NN. Depression rating scales in Parkinson's disease: A critical review updating recent literature. J Affect Disord. (2015) 184:216-24. doi: 10.1016/j.jad.2015.05.059

42. Stiasny-Kolster K, Mayer G, Schafer S, Moller JC, Heinzel-Gutenbrunner $\mathrm{M}$, Oertel WH. The REM sleep behavior disorder screening questionnairea new diagnostic instrument. Mov Disord. (2007) 22:2386-93. doi: $10.1002 / \mathrm{mds} .21740$.

43. Mahajan A, Rosenthal LS, Gamaldo C, Salas RE, Pontone GM, McCoy A, et al. REM sleep behavior and motor findings in Parkinson's disease: a cross-sectional analysis. Tremor Other Hyperkinet. Mov. (2014) 4:245. doi: $10.7916 / \mathrm{d} 84 \mathrm{~b} 2 \mathrm{zdf}$

44. Leemans A, Jeurissen B, Sijbers J, Jones D. (2009). ExploreDTI: a graphical toolbox for processing, analyzing, and visualizing diffusion MR data. In: 17th Annual Meeting of Intl Soc Mag Reson Med (Hawaii), p. 3537.

45. Yeh FC, Tseng WY. NTU-90: a high angular resolution brain atlas constructed by q-space diffeomorphic reconstruction. Neuroimage (2011) 58:91-9. doi: 10.1016/j.neuroimage.2011.06.021

46. Yeh FC, Tang PF, Tseng WYI. Diffusion MRI connectometry automatically reveals affected fiber pathways in individuals with chronic stroke. Neuroimage Clin. (2013) 2:912-21. doi: 10.1016/j.nicl.2013.06.014

47. Yeh FC, Tseng WYI. Sparse solution of fiber orientation distribution function by diffusion decomposition. PLoS ONE (2013) 8:e75747. doi: 10.1371/journal.pone.0075747

48. Yeh FC, Verstynen TD, Wang Y, Fernández-Miranda JC, Tseng WYI. Deterministic diffusion fiber tracking improved by quantitative anisotropy. PLoS ONE (2013) 8:e80713. doi: 10.1371/journal.pone.0080713

49. Slow EJ, Postuma RB, Lang AE. Implications of nocturnal symptoms towards the early diagnosis of Parkinson's disease. J Neural Transm. (2014) 121:49-57. doi: 10.1007/s00702-014-1168-4

50. Wedeen VJ, Wang R, Schmahmann JD, Benner T, Tseng W, Dai $\mathrm{G}$, et al. Diffusion spectrum magnetic resonance imaging (DSI) tractography of crossing fibers. Neuroimage (2008) 41:1267-77. doi: 10.1016/j.neuroimage.2008.03.036

51. Reiser MF, Semmler W, Hricak H. editors. Magnetic Resonance Tomography. Springer Science \& Business Media (2007).

52. Verkhratsky A, Parpura V, Pekna M, Pekny M, Sofroniew M. (2014). Glia in the pathogenesis of neurodegenerative diseases. Biochem Soc Trans. (2014) 42:1291-301. doi: 10.1042/BST20140107

53. Brück D, Wenning GK, Stefanova N, Fellner L. Glia and alpha-synuclein in neurodegeneration: a complex interaction. Neurobiol Dis. (2016) 85:262-74. doi: 10.1016/j.nbd.2015.03.003

54. Liu B, Jau-Shyong H. Roles of microglia in inflammation-mediated neurodegeneration: models, mechanisms, and therapeutic interventions for Parkinson's disease. J Pharmacol Exp Therapeut. (2003) 304:1-7. doi: 10.1124/jpet.102.035048

55. Hattori T, Orimo S, Aoki S, Ito K, Abe O, Amano A, et al. Cognitive status correlates with white matter alteration in Parkinson's disease. Hum Brain Mapp. (2012) 33:727-39. doi: 10.1002/hbm.21245

56. Melzer TR, Watts R, MacAskill MR, Pitcher TL, Livingston L, Keenan RJ, et al. White matter microstructure deteriorates across cognitive stages in Parkinson disease. Neurology (2013) 80:1841-9. doi: 10.1212/WNL.0b013e3182929f62

57. Koshimori Y, Segura B, Christopher L, Lobaugh N, Duff-Canning S, Mizrahi R, et al. Imaging changes associated with cognitive abnormalities in Parkinson's disease. Brain Struct Funct. (2015) 220:2249-61. doi: 10.1007/s00429-014-0785-x 
58. Duncan GW, Firbank MJ, Yarnall AJ, Khoo TK, Brooks DJ, Barker RA, et al. Gray and white matter imaging: A biomarker for cognitive impairment in early Parkinson's disease? Mov Disord. (2016) 31:103-10. doi: $10.1002 / \mathrm{mds} .26312$

59. Canu E, Agosta F, Sarasso E, Volontè MA, Basaia S, Stojkovic T, et al. Brain structural and functional connectivity in Parkinson's disease with freezing of gait. Hum Brain Mapp. (2015) 36:5064-78. doi: 10.1002/hbm.22994

60. Vercruysse S, Leunissen I, Vervoort G, Vandenberghe W, Swinnen S, Nieuwboer A. Microstructural changes in white matter associated with freezing of gait in Parkinson's disease. Mov Disord. (2015) 30:567-76. doi: $10.1002 / \mathrm{mds} .26130$

61. Lee E, Lee JE, Yoo K, Hong JY., Oh J, Sunwoo MK, et al. Neural correlates of progressive reduction of bradykinesia in de novo Parkinson's disease. Parkinsonism Relat Disord. (2014) 20:1376-81. doi: 10.1016/j.parkreldis.2014.09.027

62. Gu Q, Huang P, Xuan M, Xu X, Li D, Sun J, et al. Greater loss of white matter integrity in postural instability and gait difficulty subtype of Parkinson's disease. Can J Neurol Sci. (2014) 41:763-8. doi: 10.1017/cjn.2014.34

63. Huang P, Xu X, Gu Q, Xuan M, Yu X, Luo W, et al. Disrupted white matter integrity in depressed versus non-depressed Parkinson's disease patients: a tract-based spatial statistics study. J Neurol Sci. (2014) 346:145-8. doi: 10.1016/j.jns.2014.08.011

64. Liao Y, Huang X, Wu Q, Yang C, Kuang W, Du M, et al. Is depression a disconnection syndrome? Meta-analysis of diffusion tensor imaging studies in patients with MDD. J Psychiatry Neurosci. (2013) 38:49-56. doi: 10.1503/jpn.110180

65. Ghazi Sherbaf F, Same K, Aarabi MH. High angular resolution diffusion imaging correlates of depression in Parkinson's disease: a connectometry study. Acta Neurol Belg. (2018) doi: 10.1007/s13760-018-0937-5. [Epub ahead of print].

66. Catani M, Jones DK, Donato R, Ffytche DH. Occipito-temporal connections in the human brain. Brain (2003) 126:2093-107. doi: 10.1093/brain/awg203

67. Ross ED. Sensory-specific and fractional disorders of recent memory in man: I. isolated loss of visual recent memory. Arch Neurol. (1980) 37:193-200. doi: 10.1001/archneur.1980.00500530031001

68. Bauer RM. Visual hypoemotionality as a symptom of visuallimbic disconnection in man. Arch Neurol. (1982) 39:702-8. doi: 10.1001/archneur.1982.00510230028009

69. Wu JY, Zhang Y, Wu WB, Hu G, Xu Y. Impaired long contact white matter fibers integrity is related to depression in Parkinson's disease. CNS Neurosci Ther (2017) 24:108-14. doi: 10.1111/cns.12778

70. Hama S, Yamashita H, Shigenobu M, Watanabe A, Kurisu K, Yamawaki S, et al. Post-stroke affective or apathetic depression and lesion location: left frontal lobe and bilateral basal ganglia. Eur Arch Psychiatry Clin Neurosci. (2007) 257:149-52. doi: 10.1007/s00406-006-0698-7

71. Foster PS, Drago V, Crucian GP, Sullivan WK, Rhodes RD, Shenal $\mathrm{BV}$, et al. Anxiety and depression severity are related to right but not left onset Parkinson's disease duration. J Neurol Sci. (2011) 305:131-5. doi: 10.1016/j.jns.2011.02.023

72. Ford AH, Duncan GW, Firbank MJ, Yarnall AJ, Khoo TK, Burn DJ, et al. Rapid eye movement sleep behavior disorder in Parkinson's disease: magnetic resonance imaging study. Mov Disord. (2013) 28:832-6. doi: $10.1002 / \mathrm{mds} .25367$

73. Nofzinger EA, Mintun MA, Wiseman M, Kupfer DJ, Moore RY. Forebrain activation in REM sleep: an FDG PET study. Brain Res. (1997) 770:192-201. doi: 10.1016/S0006-8993(97)00807-X

74. Vogt BA, Laureys S. Posterior cingulate, precuneal and retrosplenial cortices: cytology and components of the neural network correlates of consciousness. Prog Brain Res. (2005) 150:205-17. doi: 10.1016/S0079-6123(05)50015-3

75. Ebert D, Ebmeier KP. The role of the cingulate gyrus in depression: from functional anatomy to neurochemistry. Biol Psychiatry (1996) 39:1044-50. doi: 10.1016/0006-3223(95)00320-7

76. Scherfler C, Frauscher B, Schocke M, Iranzo A, Gschliesser V, Seppi K, et al. White and gray matter abnormalities in idiopathic rapid eye movement sleep behavior disorder: a diffusion-tensor imaging and voxel-based morphometry study. Ann Neurol. (2011) 69:400-7. doi: 10.1002/ana.22245

77. Zgaljardic DJ, Borod JC, Foldi NS, Mattis P. A review of the cognitive and behavioral sequelae of Parkinson's disease: relationship to frontostriatal circuitry. Cogn Behav Neurol. (2003) 16:193-210. doi: 10.1097/00146965-200312000-00001

78. Matsui H, Nishinaka K, Oda M, Niikawa H, Komatsu K, Kubori T, et al. Depression in Parkinson's disease. J Neurol. (2007) 254:1170-3. doi: 10.1007/s00415-006-0236-6

79. Kostić VS, Filippi M. Neuroanatomical correlates of depression and apathy in Parkinson's disease: magnetic resonance imaging studies. J Neurol Sci. (2011) 310:61-3. doi: 10.1016/j.jns.2011.05.036

80. Wen MC, Chan L, Tan L, Tan E. Depression, anxiety, and apathy in Parkinson's disease: insights from neuroimaging studies. Eur J Neurol. (2016) 23:1001-19. doi: 10.1111/ene.13002

81. Taylor WD, Kudra K, Zhao Z, Steffens DC, MacFall JR. Cingulum bundle white matter lesions influence antidepressant response in late-life depression: a pilot study. J Affect Disord. (2014) 162:8-11. doi: 10.1016/j.jad.2014.03.031

82. Fox MD, Buckner RL, White MP, Greicius MD, Pascual-Leone A. Efficacy of transcranial magnetic stimulation targets for depression is related to intrinsic functional connectivity with the subgenual cingulate. Biol Psychiatry (2012) 72:595-603. doi: 10.1016/j.biopsych.2012.04.028

83. Boucetta S, Salimi A, Dadar M, Jones BE, Collins DL, Dang-Vu TT. Structural brain alterations associated with rapid eye movement sleep behavior disorder in Parkinson's disease. Sci Rep. (2016) 6:srep26782. doi: $10.1038 /$ srep26782

84. Ansari M, Rahmani F, Dolatshahi M, Pooyan A, Aarabi MH. Brain pathway differences between Parkinson's disease patients with and without REM sleep behavior disorder. Sleep Breath. (2017) 21:155-61. doi: 10.1007/s11325-016-1435-8

85. Funnell MG, Corballis PM, Gazzaniga MS. Insights into the functional specificity of the human corpus callosum. Brain (2000) 123:920-6. doi: 10.1093/brain/123.5.920

86. Bloom JS, Hynd GW. The role of the corpus callosum in interhemispheric transfer of information: excitation or inhibition? Neuropsychol Rev. (2005) 15:59-71. doi: 10.1007/s11065-005-6252-y

87. Li XR, Ren YD, Cao B, Huang XL. Analysis of white matter characteristics with tract-based spatial statistics according to diffusion tensor imaging in early Parkinson's disease. Neurosci Lett. (2017) 675:127-32. doi: 10.1016/j.neulet.2017.11.064

88. Galantucci S, Agosta F, Stankovic I, Petrovic I, Stojkovic T, Kostic V, et al. Corpus callosum damage and motor function in Parkinson's disease", in: European Journal of Neurology: WILEY-BLACKWELL 111 RIVER ST, HOBOKEN 07030-5774, NJ USA), 120-120. (2014).

89. Chan LL, Ng KM, Rumpel H, Fook-Chong S, Li HH, Tan EK Transcallosal diffusion tensor abnormalities in predominant gait disorder parkinsonism. Parkinsonism Relat Disord. (2014) 20:53-9. doi: 10.1016/j.parkreldis.2013.09.017

90. Lewis S, Foltynie T, Blackwell A, Robbins T, Owen A, Barker R. Heterogeneity of Parkinson's disease in the early clinical stages using a data driven approach. J Neurol Neurosurg Psychiatry (2005) 76:343-8. doi: 10.1136/jnnp.2003.033530

91. Andre P, Arrighi P. Hipnic modulation of cerebellar information processing: implications for the cerebro-cerebellar dialogue. Cerebellum (2003) 2:84-95. doi: 10.1080/14734220309403

92. Popa D, Spolidoro M, Proville RD, Guyon N, Belliveau L, Léna C. Functional role of the cerebellum in gamma-band synchronization of the sensory and motor cortices. J Neurosci. (2013) 33:6552-6. doi: 10.1523/JNEUROSCI.5521-12.2013

93. Canto CB, Onuki Y, Bruinsma B, van der Werf YD, De Zeeuw CI. The Sleeping Cerebellum. Trends Neurosci. (2017) 40:309-23. doi: 10.1016/j.tins.2017.03.001

94. Hanyu H, Inoue Y, Sakurai H, Kanetaka H, Nakamura M, Miyamoto T, et al. Voxel-based magnetic resonance imaging study of structural brain changes in patients with idiopathic REM sleep behavior disorder. Parkinsonism Relat Disord. (2012) 18:136-9. doi: 10.1016/j.parkreldis.2011.08.023

95. Diekelmann S. Sleep for cognitive enhancement. Front Syst Neurosci. (2014) 8:46. doi: 10.3389/fnsys.2014.00046

96. Cousins JN, El-Deredy W, Parkes LM, Hennies N, Lewis PA. Cued reactivation of motor learning during sleep leads to overnight changes in functional brain activity and connectivity. PLoS Biol. (2016) 14:e1002451. doi: 10.1371/journal.pbio.1002451 
97. Fogel S, Vien C, Karni A, Benali H, Carrier J, Doyon J. Sleep spindles: a physiological marker of age-related changes in gray matter in brain regions supporting motor skill memory consolidation. Neurobiol Aging (2017) 49:154-64. doi: 10.1016/j.neurobiolaging.2016.10.009

98. Heller J, Brcina N, Dogan I, Holtbernd F, Romanzetti S, Schulz JB, et al. Brain imaging findings in idiopathic REM sleep behavior disorder (RBD)-a systematic review on potential biomarkers for neurodegeneration. Sleep Med Rev. (2017) 34:23-33. doi: 10.1016/j.smrv.2016.06.006

99. Holtbernd F, Gagnon JF, Postuma RB, Ma Y, Tang CC, Feigin A, et al. Abnormal metabolic network activity in REM sleep behavior disorder. Neurology (2014) 82:620-7. doi: 10.1212/WNL.0000000000000130

100. Schmahmann JD, Sherman JC. The cerebellar cognitive affective syndrome. Brain (1998) 121:561-79. doi: 10.1093/brain/121.4.561

101. Lekeu F, Marczewski P, Van der Linden M, Collette F, Degueldre C, Del Fiore $\mathrm{G}$, et al. Effects of incidental and intentional feature binding on recognition: a behavioural and PET activation study. Neuropsychologia (2002) 40:131-44. doi: 10.1016/S0028-3932(01)00088-4

102. Smith KA, Ploghaus A, Cowen PJ, McCleery JM, Goodwin, GM, Smith $S$, et al. Cerebellar responses during anticipation of noxious stimuli in subjects recovered from depression. Br J Psychiatry (2002) 181:411-5. doi: 10.1192/bjp.181.5.411

103. Baillieux H, De Smet HJ, Dobbeleir A, Paquier PF, De Deyn PP, Mariën P. Cognitive and affective disturbances following focal cerebellar damage in adults: a neuropsychological and SPECT study. Cortex (2010) 46:869-79. doi: 10.1016/j.cortex.2009.09.002

104. Doron KW, Funk CM, Glickstein M. Fronto-cerebellar circuits and eye movement control: a diffusion imaging tractography study of human cortico-pontine projections. Brain Res. (2010) 1307:63-71. doi: 10.1016/j.brainres.2009.10.029

105. Peng HJ, Zheng HR, Ning YP, Zhang Y, Shan BC, Zhang L, et al. Abnormalities of cortical-limbic-cerebellar white matter networks may contribute to treatment-resistant depression: a diffusion tensor imaging study. BMC Psychiatry (2013) 13:72. doi: 10.1186/1471-244X-13-72

106. Lee GP, Meador KJ, Loring DW, Allison JD, Brown WS, Paul LK, et al. Neural substrates of emotion as revealed by functional magnetic resonance imaging. Cogn Behav Neurol. (2004) 17:9-17. doi: 10.1097/00146965-200403000-00002

107. Zhao L, Wang Y, Jia Y, Zhong S, Sun Y, Zhou Z, et al. Cerebellar microstructural abnormalities in bipolar depression and unipolar depression: a diffusion kurtosis and perfusion imaging study. I Affect Disord. (2016) 195:21-31. doi: 10.1016/j.jad.2016.01.042

108. Skidmore F, Yang M, Baxter L, Von Deneen K, Collingwood J, He G, et al. Apathy, depression, and motor symptoms have distinct and separable resting activity patterns in idiopathic Parkinson disease. Neuroimage (2013) 81:484-95. doi: 10.1016/j.neuroimage.2011.07.012

109. Wen X, Wu X, Liu J, Li K, Yao L. Abnormal baseline brain activity in non-depressed Parkinson's disease and depressed Parkinson's disease: a resting-state functional magnetic resonance imaging study. PLoS ONE (2013) 8:e63691. doi: 10.1371/journal.pone.0063691

110. Lee DY, Fletcher E, Carmichael OT, Singh B, Mungas D, Reed B, et al. Sub-regional hippocampal injury is associated with fornix degeneration in Alzheimer's disease. Front Aging Neurosci. (2012) 4:1. doi: 10.3389/fnagi.2012.00001

111. Hescham S, Lim LW, Jahanshahi A, Steinbusch HW, Prickaerts J, Blokland A, et al. Deep brain stimulation of the forniceal area enhances memory functions in experimental dementia: the role of stimulation parameters. Brain Stimul. (2013) 6:72-7. doi: 10.1016/j.brs.2012.01.008

112. Douet V, Chang L. Fornix as an imaging marker for episodic memory deficits in healthy aging and in various neurological disorders. Front Aging Neurosci. (2015) 6:343. doi: 10.3389/fnagi.2014.00343

113. Fletcher E, Raman M, Huebner P, Liu A, Mungas D, Carmichael O, et al. Loss of fornix white matter volume as a predictor of cognitive impairment in cognitively normal elderly individuals. JAMA Neurol. (2013) 70:1389-95. doi: 10.1001/jamaneurol.2013.3263

114. Duffy SL, Paradise M, Hickie IB, Lewis SJ, Naismith SL, Lagopoulos J. Cognitive impairment with and without depression history: an analysis of white matter microstructure. J Psychiatry Neurosci. (2014) 39:135-43. doi: $10.1503 /$ jpn. 130079
115. Hoogenboom WS, Perlis RH, Smoller JW, Zeng-Treitler Q, Gainer VS, Murphy SN, et al. Limbic system white matter microstructure and longterm treatment outcome in major depressive disorder: a diffusion tensor imaging study using legacy data. World J Biol Psychiatry (2014) 15:122-34. doi: 10.3109/15622975.2012.669499

116. Kim HJ, Kim SJ, Kim HS, Choi CG, Kim N, Han S, et al. Alterations of mean diffusivity in brain white matter and deep gray matter in Parkinson's disease. Neurosci Lett (2013) 550:64-8. doi: 10.1016/j.neulet.2013. 06.050

117. Zheng Z, Shemmassian S, Wijekoon C, Kim W, Bookheimer SY, Pouratian N. DTI correlates of distinct cognitive impairments in Parkinson's disease. Hum Brain Mapp. (2014) 35:1325-33. doi: 10.1002/hbm.22256

118. Koyama Y, Takahashi K, Kodama T, Kayama, Y. State-dependent activity of neurons in the perifornical hypothalamic area during sleep and waking. Neuroscience (2003) 119:1209-19. doi: 10.1016/S0306-4522(03) 00173-8

119. Lu JW, Fenik VB, Branconi JL, Mann GL, Rukhadze I, Kubin L. Disinhibition of perifornical hypothalamic neurones activates noradrenergic neurones and blocks pontine carbachol-induced REM sleep-like episodes in rats. J Physiol. (2007) 582:553-67. doi: 10.1113/jphysiol.2007. 127613

120. Gerashchenko D, Murillo-Rodriguez E, Lin L, Xu M, Hallett L, Nishino $\mathrm{S}$, et al. Relationship between CSF hypocretin levels and hypocretin neuronal loss. Exp Neurol. (2003). 184:1010-6. doi: 10.1016/S0014-4886(03) 00388-1

121. Chen L, Thakkar MM, Winston S, Bolortuya Y, Basheer R, McCarley RW. REM sleep changes in rats induced by siRNA-mediated orexin knockdown. Eur J Neurosci. (2006) 24:2039-48. doi: 10.1111/j.1460-9568.2006. 05058.x

122. Peyron C, Faraco J, Rogers W, Ripley, B, Overeem, S, Charnay, Y, et al. A mutation in a case of early onset narcolepsy and a generalized absence of hypocretin peptides in human narcoleptic brains. Nat Med. (2000) 6:991-7. doi: 10.1038/79690

123. Kiyashchenko LI, Mileykovskiy BY, Maidment N, Lam HA, Wu MF, John J, et al. Release of hypocretin (orexin) during waking and sleep states. J Neurosci. (2002) 22:5282-6. doi: 10.1523/JNEUROSCI.22-13-05282.2002

124. Fronczek R, Overeem S, Lee SY, Hegeman IM, Van Pelt J, Van Duinen SG, et al. Hypocretin (orexin) loss in Parkinson's disease. Brain (2002) 130:1577-85. doi: 10.1093/brain/awm090

125. Unger MM, Belke M, Menzler K, Heverhagen JT, Keil B, Stiasny-Kolster $\mathrm{K}$, et al. Diffusion tensor imaging in idiopathic REM sleep behavior disorder reveals microstructural changes in the brainstem, substantia nigra, olfactory region, and other brain regions. Sleep (2010) 33:767-73. doi: 10.1093/sleep/33.6.767

126. Matsui H, Nishinaka K, Oda M, Niikawa H, Komatsu K, Kubori T, et al. Disruptions of the fornix fiber in Parkinsonian patients with excessive daytime sleepiness. Parkinsonism Relat Disord. (2006) 12:319-22. doi: 10.1016/j.parkreldis.2006.01.007

127. Cruz-Gómez Á, Belenguer-Benavides A, Martinez-Bronchal B, FittipaldiMárquez M, Forn C. Structural and functional changes of the hippocampus in patients with multiple sclerosis and their relationship with memory processes. Rev Neurol. (2016) 62:6-12. doi: 10.1148/radiol.10091433

128. Bohlhalter S, Abela E, Weniger D, Weder B. Impaired verbal memory in Parkinson disease: relationship to prefrontal dysfunction and somatosensory discrimination. Behav Brain Funct. (2009) 5:49. doi: 10.1186/17449081-5-49

129. Beyer MK, Bronnick KS, Hwang KS, Bergsland N, Tysnes OB, Larsen JP, et al. Verbal memory is associated with structural hippocampal changes in newly diagnosed Parkinson9s disease. J Neurol Neurosurg Psychiatr. (2013) 84:23-8. doi: 10.1136/jnnp-2012-303054

130. Segura B, Ibarretxe-Bilbao N, Sala-Llonch R, Baggio HC, Martí MJ, Valldeoriola $\mathrm{F}$, et al. Progressive changes in a recognition memory network in Parkinson's disease. J Neurol Neurosurg Psychiatr. (2013) 84:370-8. doi: 10.1136/jnnp-2012-302822

131. Chiaravalloti ND, Ibarretxe-Bilbao N, DeLuca J, Rusu O, Pena J, GarcíaGorostiaga I, et al. The source of the memory impairment in Parkinson's disease: acquisition versus retrieval. Mov Disord. (2014) 29:765-71. doi: $10.1002 / \mathrm{mds} .25842$ 
132. Lucas-Jiménez O, Díez-Cirarda M, Ojeda N, Pe-a J, Cabrera-Zubizarreta A, Ibarretxe-Bilbao N. Verbal memory in parkinson's disease: a combined DTI and fMRI study. J Parkinsons Dis. (2015) 5:793-804. doi: 10.3233/JPD-150623

133. Pushpanathan ME, Loftus AM, Thomas MG, Gasson N, Bucks, RS. The relationship between sleep and cognition in Parkinson's disease: a meta-analysis. Sleep Med Rev. (2016) 26:21-32. doi: 10.1016/j.smrv.2015. 04.003

134. Sankar A, Adams TM, Costafreda SG, Marangell LB, Fu CH. Effects of antidepressant therapy on neural components of verbal working memory in depression. J Psychopharmacol. (2017) 31:1176-83. doi: $10.1177 / 0269881117724594$
Conflict of Interest Statement: The authors declare that the research was conducted in the absence of any commercial or financial relationships that could be construed as a potential conflict of interest.

Copyright () 2018 Ghazi Sherbaf, Rostam Abadi, Mojtahed Zadeh, AshrafGanjouei, Sanjari Moghaddam and Aarabi. This is an open-access article distributed under the terms of the Creative Commons Attribution License (CC $B Y)$. The use, distribution or reproduction in other forums is permitted, provided the original author(s) and the copyright owner are credited and that the original publication in this journal is cited, in accordance with accepted academic practice. No use, distribution or reproduction is permitted which does not comply with these terms. 